3 Research Square

\title{
Using GAM regression analysis to identify proper heat-warning thresholds: a population-based observational study
}

Shih-Chun Candice Lung ( $\nabla$ sclung@rcec.sinica.edu.tw )

Academia Sinica https://orcid.org/0000-0002-4227-0469

Jou-Chen Joy Yeh

Research Center for Environmental Changes Academia Sinica

Jing-Shiang Hwang

Institute of Statistical Sciences Academia Sinica

\section{Research}

Keywords: Sustainable Development Goal 3, extreme events and health, socio-demographic factors and health, heat-health warning system, heat-health threshold identification

Posted Date: April 5th, 2021

DOI: https://doi.org/10.21203/rs.3.rs-384410/v1

License: (a) (1) This work is licensed under a Creative Commons Attribution 4.0 International License.

Read Full License 


\section{Using GAM regression analysis to identify proper heat-warning thresholds:}

\section{a population-based observational study}

Shih-Chun Candice Lung ${ }^{\text {abc* }}$, Jou-Chen Joy Yeha, Jing-Shiang Hwang ${ }^{\text {d* }}$

${ }^{a}$ Research Center for Environmental Changes, Academia Sinica, Taipei, Taiwan.

${ }^{\mathrm{b}}$ Department of Atmospheric Sciences, National Taiwan University, Taipei, Taiwan.

'Institute of Environmental and Occupational Health Sciences, National Taiwan University, Taipei, Taiwan.

${ }^{\mathrm{d}}$ Institute of Statistical Science, Academia Sinica, Taipei, Taiwan.

*Corresponding author, Shih-Chun Candice Lung, Research Center for Environmental Changes, Academia Sinica, No. 128, Sec. 2, Academia Rd, Nangang, Taipei, Taiwan 11529; Tel: 8862-27875908, Fax: 886-2-27833584, email:sclung@,rcec.sinica.edu.tw.

${ }^{*}$ Corresponding author, Jing-Shiang Hwang, Institute of Statistical Science, Academia Sinica, No. 128, Sec. 2, Academia Rd, Nangang, Taipei, Taiwan; 11529; Tel: 886-2-27875700, Fax: 886-22788-6833, email: jshwang@stat.sinica.edu.tw. 


\begin{abstract}
Background: Climate change has augmented heat-related illnesses and deaths. Selecting proper thresholds in a heat-warning system is critical to reducing health risks.

Methods: This work evaluates the applicability of a modified generalized additive model (GAM) at different spatial scales, and identifies proper heat-warning thresholds using empirical morbidity and mortality records of 18 years from a population database and taking into account substantial health risk increases of the lag effects of 0-2 days. Reference-adjusted risk ratio (RaRR), i.e., risk ratio of threshold candidates against that of a reference, was respectively evaluated for heat-related emergency and hospital visits and all-cause mortality. The threshold with the highest RaRR among the candidates with infrequent occurrence is potentially the best one. Wet-bulb globe temperature (WBGT) and temperature were both used heat indicator in the model for comparison.
\end{abstract}

Results: It was found that WBGT is a more sensitive heat-health indicator than temperature. The highest RaRR with WBGT for the whole Taiwan island was observed to shift from lag 0 in emergency visits (1.44) to lags $0-1$ in hospital visits (1.18) and also to lag 1 in all-cause mortality (1.04). For different age groups, children had the highest RaRR with WBGT of emergency visits on lag 0 (1.87) while the elderly had the highest RaRR for all-cause mortality on lag 0 (1.04), for hospital visits on lag 1 (1.23), and for emergency visits on lag 2 (1.38), respectively. Emergency visit is the most sensitive heat-related health record and should thus be employed, if available, to select heat-warning threshold. With the highest RaRR in emergency visits and the occurring frequency considered, the best area-specific thresholds can be chosen for various sizes of population at-risk. The novel RaRR allows comparison of health risks across different categories, providing a solid scientific basis for threshold selection. 
Conclusions: This work demonstrated the feasibility and flexibility of the proposed approach which considers substantial enhancement of health risks on lags 0 to 2, removes the rare-event interference, and accommodates at-risk populations of different sizes. This methodology can be applied by authorities worldwide for selecting proper heat-health thresholds according to their own morbidity/mortality records.

Keywords: Sustainable Development Goal 3, extreme events and health, socio-demographic factors and health, heat-health warning system, heat-health threshold identification 


\section{Background}

In face of climate emergency (1), adaptation is as important as mitigation. Record-breaking temperatures have occurred more frequently with longer durations worldwide (2-4); the resulted high heat-related casualty highlights the urgency and importance of establishing a heat warning system to meet the third Sustainable Development Goal set by the United Nations (5) for health risk reduction due to rapid climate change. The disastrous heat waves in Europe in 2003 demonstrated the necessity of establishing a heat warning system to prevent significant casualty even in developed countries (6). The tens of thousands of deaths during the heat waves in India and Pakistan in 2015 further revealed that an effective heat warning system is even more critical in developing countries where health care systems lagged behind those in developed countries $(7,8)$. While a heat warning system has long been recognized as the most effective way to reduce heat-related health risks $(9,10)$, the challenge remains in selecting a proper heat indicator and an appropriate threshold with sound scientific evidences (11), which could trigger adequate responsive actions from the authorities to prevent high casualty and advise people for self-protection. This paper aims at providing a systematic approach to assisting authorities worldwide in identifying appropriate heat-warning thresholds.

The determination of a proper threshold for issuing heat warning should ideally be supported with historical records of "significant" heat-health impacts. As emphasized in our earlier work (11), most heat-health studies were in fact assessing the starting points in the right arm of the U-shaped or Vshaped heat/cold-related health impacts just outside the comfort zone of human being, which is associated with statistically but not substantially increased health impacts. Issuing health warning according to these starting points would be too frequent, thus losing the attention of the general public while exhausting the resources of the authorities. Such starting points in practice are not appropriate thresholds for issuance of heat warning which should be associated with substantial health impacts; and intervention measures thus triggered should serve to reduce significant health risks. Up to now, only a few studies focused on providing a systematic approach to assisting governmental agencies in 
establishing proper heat-warning thresholds. With data from USA, Petitti et al. (12) attempted to identify multiple trigger points at which heat-health intervention measures might be activated, using 95\% confidence interval as a criterion for selecting increasing risk temperature and excess risk temperature above the minimum risk temperature. Our earlier work proposed a more straightforward approach to simultaneously evaluating proper thresholds with substantial health risk increments according to local health records, thus providing a systematic method of selecting proper thresholds for different countries located in different climate zones (11).

On the basis of our previous work, this study further modifies the approach to selecting proper thresholds, not only with emphasis on substantial health risk increases but also with both lag effects $(0$ to 2 days) and at-risk populations of different sizes taken into account. The flexibility of applying this useful scientific tool at different spatial resolutions for assisting the authorities to establish a heat warning system with solid health-based evidences is demonstrated. As evaluated in our previous work (11), wet-bulb globe temperature (WBGT), compared against both temperature and apparent temperature, showed the most obvious increasing trends for three different health outcomes in Taiwan population, making it a proper heat-health indicator. Moreover, WBGT comprises four essential meteorological parameters related to heat stress, namely, temperature, relative humidity ( $\mathrm{RH} \%)$, wind speed, and solar radiation. A proper heat-warning indicator should be related to human physiological changes with extensive physiological-based evidences (13) rather than considering only subjective thermal comfort such as apparent temperature. In addition, WBGT has been used for six decades as an indicator for preventing heat-stress-related health impacts in workplaces; and studies in occupational health have demonstrated the relationships between WBGT and heat-related health outcomes of workers (13-18). Increasing evidences also showed that WBGT is a suitable heat-health indicator for the general public as well (19-23). However, the warning thresholds for workers cannot be directly applied to the general public with vulnerable populations, such as the elderly and children. Thus, this work aims at identifying proper WBGT thresholds for the general public on the basis of both heat- 
related morbidity and all-cause mortality records.

In summary, to fill the scientific gap of a feasible health-evidence-based method for the authorities to identify proper thresholds of a heat warning system, the objectives of this work are as follows. First, a modified statistical model is proposed for identifying proper thresholds, taking into consideration one- to three-day substantial health risk increases on the basis of damage coefficients of heat-health relationships above the thresholds, with data from Taiwan for illustration. Secondly, proper thresholds are selected using different health records (heat-related emergency and hospital visits as well as allcause mortality) and with both WBGT and temperature used as a heat indicator for comparison. Thirdly, the applicability of the proposed method is examined at different spatial scales with at-risk populations of different sizes and heat events of different frequencies. Findings of this study should provide useful reference and assistance to central and local governments worldwide in selecting proper thresholds according to their own health records.

\section{Methods}

Records on daily emergency and hospital visits of heat-related illness between 2000 and 2017 were obtained from the database of the Health and Welfare Data Science Center of the Ministry of Health and Welfare. This database contains hospital visit information of almost the entire population of Taiwan (23.71 million), including age and sex of patients as well as hospital locations. Cases of heat-related illness (according to the 9th Revision of the International Classification of Diseases (ICD9): 992 including heat stroke and heat exhaustion for 2000-2015 data, and ICD10: T67.0XXA-T67.9XXA for 2016-2017 data) were used in this work. All-cause mortality counts (excluding accidents and suicide) between 2008 and 2017 were obtained from the Taiwan National Mortality Registry. Data before 2008 were not used because the location of death was not specified.

Hourly meteorological data from 2000 to 2017 were obtained from 20 non-mountainous $(<500$ $\mathrm{m}$ above sea level) stations of the Central Weather Bureau in Taiwan. Daily maximum temperatures of 
these stations were averaged for analysis on Taiwan as a whole. To evaluate the spatial difference in heat-health relationships and to assess the flexibility of the present method at different spatial scales, Taiwan island is divided into sub-regions, namely North, Central, South and East Taiwan (Additional File Figure A1). Geographically separated by mountain ranges, North, Central and South Taiwan are mainly on the western side of the island, with much higher population density compared with the eastern side. The population and area of these sub-regions in 2017 are listed in Table 1. There are 6, 2, 6, and 6 weather stations located in North, Central, South, and East Taiwan, respectively.

WBGT is a weighed combination of dry-bulb temperature, natural wet-bulb temperature and globe temperature (13). However, natural wet-bulb temperature and globe temperature were not provided by routine meteorological measurements. Nevertheless, equations for calculating WBGT according to fundamental principles of heat and mass transfer with standard meteorological data have been derived and validated (24) Thus, with inputs of routine meteorological measurements of hourly temperature, $\mathrm{RH} \%$, wind speed, and solar radiation, WBGT can be calculated. The daily maximum WBGTs of these stations were also averaged for analysis.

In the heat-health model, confounders such as air pollutants (25) were adjusted using daily means of $\mathrm{PM}_{2.5}$ levels from 2000 to 2017; $\mathrm{PM}_{2.5}$ was used because it is currently the most concerned pollutant in Taiwan and has high correlation with other pollutants. $\mathrm{PM}_{2.5}$ levels were obtained from 58 ambient air-quality monitoring stations and 4 industrial stations located in populated areas (population density close to or above median population density of Taiwan in 2017,618 people $/ \mathrm{km}^{2}$, Table 1 ) of the Environmental Protection Administration, Taiwan, between 2000 and 2017. For North, Central, South, and East Taiwan, there are 25, 11, 22, and 4 stations, respectively, included in the present analysis. 
Table 1 Characteristics of Taiwan and sub-regions with 99.5 percentile of WBGT and temperature and chosen limits

\begin{tabular}{|c|c|c|c|c|c|c|}
\hline & & Taiwan & North & Central & South & East \\
\hline Pop & lation & 23316818 & 10776529 & 4570579 & 6964326 & 1005384 \\
\hline Are & $\left(\mathrm{km}^{2}\right)$ & 355887 & 7030 & 7396 & 11174 & 10287 \\
\hline $\begin{array}{r}\text { Populat } \\
\text { (Pop. }\end{array}$ & $\begin{array}{l}\text { on density } \\
\text { er } \mathrm{km}^{2} \text { ) }\end{array}$ & 650 & 1533 & 618 & 623 & 98 \\
\hline & $\begin{array}{c}99.5 \text { percentile } \\
(2000-2017)\end{array}$ & 33.2 & 34.3 & 35.0 & 33.2 & 33.4 \\
\hline WBGT & $\begin{array}{l}99.5 \text { percentile } \\
(2008-2017)^{\mathrm{a}}\end{array}$ & 33.2 & 34.3 & 35.4 & 33.2 & 33.4 \\
\hline & Chosen limit & 33.0 & 34.5 & 35.0 & 33.0 & 33.5 \\
\hline & $\begin{array}{c}99.5 \text { percentile } \\
(2000-2017)\end{array}$ & 34.1 & 35.5 & 35.2 & 34.3 & 34.0 \\
\hline Temperature & $\begin{array}{l}99.5 \text { percentile } \\
(2008-2017)^{\mathrm{a}}\end{array}$ & 34.2 & 35.6 & 35.3 & 34.3 & 33.9 \\
\hline & Chosen limit & 34.0 & 35.5 & 35.0 & 34.5 & 34.0 \\
\hline
\end{tabular}

The models used in this paper were modified from our previous work (11). The present method first confirmed the linear patterns of health outcome above certain cut-points of the heat indicators, then evaluated the risk ratios (RRs) of the different threshold candidates, and compared those RRs with a reference. Finally, the numbers of days above different threshold candidates in previous years were assessed to evaluate the feasibility of designating the specific thresholds in the heat warning system. The best threshold will be chosen on the basis of RR comparison and occurring frequency. 
Only data of May to October (warm season) were used for modeling. Data of health outcomes were fitted to generalized additive models (GAMs) with Poisson distribution to examine relationships between heat indicators (denoted as $D_{t}$, WBGT or temperature) and health outcomes (denoted by $Y_{t}$, heat-related emergency visits, heat-related hospital visits, and all-cause mortality counts), with detailed description in (11). The initial model is specified as

$$
\log \left[E\left(Y_{t}\right)\right]=\alpha+f\left(D_{t}\right)+g(t)+\sum_{i=1}^{m} \lambda_{i} C_{i t}
$$

where $\alpha$ is a constant, $f\left(D_{t}\right)$ is a thin plate spline function of the heat indicator with a number of knots over days in each warm season, and $g(t)$ is another thin plate spline function of day $t$ with some number of knots for examining daily change pattern during warm seasons. Potential covariates on day $t$, denoted by $C_{i t}$, such as daily mean $\mathrm{PM}_{2.5}$ concentration, day of week, holiday, and periods prevalent with the severe acute respiratory syndrome are considered for adjustment. SAS 9.4 (SAS Institute Inc., Cary, NC, USA) and R 3.5.1 with $m g c v$ package for GAM estimations were used in the present analysis. The number of knots for $f\left(D_{t}\right)$ is automatically chosen for different models. The number of knots $k=3$ was adopted for $g(t)$ according to lower Akaike information criterion values for each warm season; hence, $g(t)$ with $k=54$ and 30 was considered for modeling all 18-year data on heatrelated emergency and hospital visits and 10-year all-cause mortalities, respectively. After obtaining the best model, the estimated smooth function $\hat{f}\left(D_{t}\right)$ was plotted to examine the heat-health relationships which did reveal a linear heat-health relationship for the heat indicator beyond certain cut-points. Then, this model was further modified for determining proper thresholds. Specifically, the daily maximum heat indicator on day $t$ in the model is replaced by $H_{t}$ which is defined as,

$$
H_{t}= \begin{cases}D_{t}-\theta, & \text { if } D_{t}>\theta \\ 0, & \text { otherwise }\end{cases}
$$

where $\theta$ is a specified threshold candidate of the heat indicator. The model is then modified as

$$
\log \left[E\left(Y_{t} \mid \theta\right)\right]=\alpha+\beta_{\theta} H_{t}+g(t)+\sum_{i=1}^{m} \lambda_{i} C_{i t} \quad \text { Eq. (2) }
$$


where $\beta_{\theta}$ is the damage coefficient associated with a unit increase of heat indicator from the chosen threshold $\theta$. The risk ratio (RR), $\left.e^{k \times \beta_{\theta}}=\mathrm{E}\left(Y_{t} \mid D_{t}=\theta+k\right) / \mathrm{E}\left(Y_{t} \mid D_{t}=b_{\theta}\right)\right)$ for any value $b_{\theta} \leq \theta$, is defined by the ratio of the expected health outcome for a $k$ unit increase over the threshold candidate compared with the expected health outcome for any heat indicator below or equal the threshold. The threshold candidates were assessed starting from $30^{\circ} \mathrm{C}$ (the lowest threshold candidate) at $0.5^{\circ} \mathrm{C}$ increments sequentially in view of higher mortality of various diseases in Taiwan at WBGT and temperature above $30^{\circ} \mathrm{C}(11,26)$. The models were repeatedly fitted with the threshold candidates till the sample size was too small, i.e., very few cases or days above the threshold candidate.

The RR values of these threshold candidates were compared with that of a reference, the chosen lowest threshold candidate denoted by $a=30^{\circ} \mathrm{C}$ in this work. The RR difference calculated as $\left[e^{\beta_{\theta}}-e^{\beta_{a}}\right] \times 100 \%$ was used in our previous work (11). This study further modified the comparison of these RRs, expressed in ratio rather than difference, to emphasize the enhancement of the expected health outcome above threshold candidates. This further-refined indicator, reference-adjusted risk ratio (RaRR), is defined as

$$
R a R R=\frac{e^{k \times \beta_{\theta}}}{e^{k \times \beta_{a}}}=\frac{E\left(Y \mid D_{t}=\theta+k\right) / E\left(Y \mid D_{t}=b_{\theta} \leq \theta\right)}{E\left(Y \mid D_{t}=a+k\right) / E\left(Y \mid D_{t}=b_{a} \leq a\right)} \quad \text { for } \theta \geq a
$$

RaRR equals to $E\left(Y \mid D_{t}=\theta+k\right) / E\left(Y \mid D_{t}=a+k\right)$, the relative expected health outcome of $k$ degree above the heat indicator candidate over that above the reference, when both the given $b_{\theta}$ and $b_{a}$ equal to the reference $a$. We determine the threshold as the candidate with the maximum of RaRR which is calculated only when $e^{\beta_{\theta}}$ is statistically significant. The selected threshold often indicates that the expected health outcome of the population exposed to WBGT or temperature above the threshold has the maximum increase among those heat indicator values above the reference. 
When the two-day lag effect is considered, the equation is modified as

$$
\log \left[\mathrm{E}\left(\mathrm{Y}_{\mathrm{t}} \mid \theta\right)\right]=\alpha+\beta_{\theta 0} H_{t}+\beta_{\theta 1} H_{t-1}+\beta_{\theta 2} H_{t-2}+\mathrm{g}(\mathrm{t})+\sum_{\mathrm{i}=1}^{\mathrm{m}} \lambda_{\mathrm{i}} \mathrm{C}_{\mathrm{it}}
$$

Moreover, in order to evaluate spatial differences of the heat-health relationship and the flexibility of this model with at-risk populations of different sizes, the above models were applied to the subregions of Taiwan. However, above certain heat indicator values, the heat-health relationships became unstable, as illustrated in the example shown in Figure 1. As seen in Figure 1(a), there exists a linear relationship of WBGT with heat-related hospital visits for the whole Taiwan island, but the number of heat-related hospital visits in Central Taiwan fluctuated when WBGT exceeded $35^{\circ} \mathrm{C}$ (Figure 1(b)). These fluctuations may be attributed to the infrequent occurrence of temperature above $35^{\circ} \mathrm{C}$ (rare events) in Central Taiwan. To avoid the impact of such rare events, the upper limit $(\delta)$ chosen for the modified model approximated the 99.5 percentile of the heat indicators in the specific sub-region (Table 1), as expressed in Eq. (5).

$\log \left[\mathrm{E}\left(\mathrm{Y}_{\mathrm{t}} \mid \theta\right)\right]=\alpha+\beta_{\theta 0} H_{t}+\beta_{\theta 1} H_{t-1}+\beta_{\theta 2} H_{t-2}+\gamma_{0} L_{t}+\gamma_{1} L_{t-1}+\gamma_{2} L_{t-2}+\mathrm{g}(\mathrm{t})+\sum_{\mathrm{i}=1}^{\mathrm{m}} \lambda_{\mathrm{i}} \mathrm{C}_{\mathrm{it}}$ Eq. (5)

where $L_{t}=\left\{\begin{array}{l}1, \quad \text { if } D_{t} \geq \delta>\theta \\ 0, \text { otherwise }\end{array}\right.$, the same for $L_{t-1}, L_{t-2}$ and $H_{t}=\left\{\begin{array}{c}D_{t}-\theta, \text { if } \delta>D_{t}>\theta \\ 0, \text { otherwise }\end{array}\right.$, the same for $H_{t-1}, H_{t-2}$.

For consistency, Eq. (5) was applied for all spatial scales in this study. The same sets of $\delta$ and $\theta$ were used for calculating $H_{t}, H_{t-1}$, and $H_{t-2}$ for each model. It should be noted that $\theta$ sometimes differs from $\delta$ only by $0.5^{\circ} \mathrm{C}$ in these models. Using data in this $0.5^{\circ} \mathrm{C}$ range to obtain 
damage coefficients covering a $1^{\circ} \mathrm{C}$ range would cause bias. Thus, the new RR between the expected health outcome for a $0.5^{\circ} \mathrm{C}$ increase, instead of the commonly used $1{ }^{\circ} \mathrm{C}$ increase, over the threshold candidate divided by the expected health outcome for that heat indicator below the threshold, represented by $e^{\beta_{\theta j} / 2}$, is used for calculating $\operatorname{RaRR}_{j}$ with lag $j=0,1,2$ to identify the threshold. For coherent comparisons among different regions and health outcomes, this new RR is used in the subsequent analysis regardless of the actual differences between $\delta$ and $\theta$ at different spatial scales.

In summary, the present method first confirmed the linear patterns of health outcome above certain cut-points of the heat indicators using Eq. (1), and then evaluated the threshold candidates with RaRR (Eq. (3)) using RR values obtained from Eq. (5) for a $0.5^{\circ} \mathrm{C}$ increase $\left(e^{\beta_{\theta j} / 2}\right)$. RaRR is the ratio of $\mathrm{RR}$ at the threshold candidate for a $0.5^{\circ} \mathrm{C}$ increase adjusted against that at a reference $\left(30^{\circ} \mathrm{C}\right)$. In addition, the historical occurring frequency above different threshold candidates were assessed to evaluate the feasibility of designating the specific thresholds in the heat warning system.

\section{Results}

Table 2 shows the summary of health and environment data in Taiwan during warm seasons between 2000 and 2017. As to health data shown in Table 2(a), for the whole Taiwan island, daily maximum heat-related emergency and hospital visits reached 73 and 1533, respectively; and daily maximum all-cause mortality was 510. In terms of sex difference, males had more heat-related emergency visits and higher daily all-cause mortality while females had more heat-related hospital visits. Among different age groups, people aged 15-64 accounted for the majority of heat-related emergency and hospital visits while those aged $\geq 65$ had the highest counts in all-cause mortality. Among different sub-regions, East Taiwan had the lowest counts while North Taiwan had the highest counts in all three health outcomes. As for environment data shown in Table 2(b), the average daily maximum WBGT and temperature during warm seasons of these 18 years for the whole Taiwan island were $33.6^{\circ} \mathrm{C}$ and $34.8^{\circ} \mathrm{C}$, respectively. The highest WBGT $\left(38.1^{\circ} \mathrm{C}\right)$ and temperature $\left(39.7^{\circ} \mathrm{C}\right)$ both 
occurred in Central Taiwan.

[Insert Table 2 here]

Table 3(a) and (b) shows RRs estimated by the modified GAMs for the whole Taiwan island with different threshold candidates of WBGT and temperature, respectively, considering the lag effects of 0-2 days. For heat-related emergency and hospital visits with lag effects of 0,1 , and 2 days, RRs showed rising trends with increase in WBGT threshold from $30^{\circ} \mathrm{C}$ to $32.5^{\circ} \mathrm{C}$ and temperature threshold from $30^{\circ} \mathrm{C}$ to $33.5^{\circ} \mathrm{C}$. Moreover, most RRs of both WBGT and temperature threshold candidates decreased from lag 0 to lag 2 . For example, at WBGT threshold of $32.5^{\circ} \mathrm{C}$, the statistically significant RRs of heat-related emergency visits were $1.82,1.31$, and 1.14 for lag effects of 0,1 , and 2 days, respectively; while their corresponding RRs of heat-related hospital visits were 1.27, 1.23, and 1.17, respectively. Similarly, at the temperature threshold of $33.5^{\circ} \mathrm{C}$, the statistically significant RRs of heatrelated emergency visits were $1.62,1.18$, and 1.15 for lag effects of 0,1 , and 2 days, respectively; while their corresponding RRs for heat-related hospital visits were 1.31, 1.20, and 1.17, respectively. In contrast, the rising trends of RR for all-cause mortality were comparatively less obvious until the highest threshold candidate for both WBGT and temperature; and there was no significant difference in RRs for lag effects of 0-2 days among all threshold candidates.

[Insert Table 3 here]

The novelty of this study is the proposed RaRR that emphasizes increases in substantial health risk against that of a reference. The proposed RaRR is calculated using the aforementioned RR values. The RaRR of different health outcomes at WBGT thresholds are presented in Tables A1 and A2 (sex/age and sub-region, respectively) while the corresponding RaRR at temperature thresholds are displayed in Tables A3 and A4. Figure 2(a)-(b) shows changes in RaRR of heat-related emergency visits at different WBGT threshold candidates for the whole Taiwan and in different sub-regions as well as for different sex and age groups, respectively. The levels of statistical significance associated with the corresponding RR are denoted with different symbols. For heat-related emergency visits, the 
highest RaRRs were seen at lag 0 (Figure 2(a)-(b), RaRR = 1.44 for the whole Taiwan, Table A1). For heat-related hospital visits, the highest RaRR for the whole Taiwan island occurred at lags 0 and 1 (both 1.18) (Figure 2(c)) while that for different sex, age and sub-regions, except for East Taiwan, occurred either at lag 0 or 1 (Figure 2(c)(d)). For all-cause mortality, the highest RaRR for the whole Taiwan island was seen at lag 1 (1.04) (Figure 2(e)). Equivalent information for heat-related hospital visits and all-cause mortality is illustrated in Figure 2(c)-(d) and Figure 2(e)-(f), respectively. Likewise, Figure 3(a)-(f) displays changes in RaRR at different temperature threshold candidates for the three different health outcomes under different categories.

Variations in RaRR among different sub-regions at both WBGT and temperature thresholds (Figures 2(a)(c)(e) and 3(a)(c)(e)) were observed, with larger variability for WBGT, indicating again that WBGT is a more sensitive heat-health indicator than temperature. For heat-related emergency visits, RaRR for different sub-regions generally tend to increase with increasing WBGT on lags 0-2, with few exceptions. North Taiwan had the highest RaRR (2.18) at WBGT of $34^{\circ} \mathrm{C}$ on lag 0 while East Taiwan has different patterns on lags 0-2 probably due to the small-sized at-risk populations. For heatrelated hospital visits, North Taiwan had the highest RaRR (1.32) at the highest threshold candidate $\left(34^{\circ} \mathrm{C}\right)$ and on lag 1 while Central and South Taiwan had the highest RaRR (1.10 and 1.24, respectively) at the highest threshold candidate $\left(34.5^{\circ} \mathrm{C}\right.$ and $32.5^{\circ} \mathrm{C}$, respectively) on lag 0 . East Taiwan again had different patterns. For all-cause mortality, South Taiwan is the only sub-region with statistically significant RR at the highest threshold candidates on all lag days.

To protect vulnerable populations is the mission of the heat warning system. This work assessed heat risks for different sex and age groups. The present findings revealed higher RaRRs of emergency visits for females on lags $0-2$ at $\mathrm{WBGT}$ of $32.5^{\circ} \mathrm{C}$ than for males; for example, higher RaRR on lag 0 was observed in females (1.55) than in males (1.41). In contrast, RaRRs of hospital visits at WBGT of $32.5^{\circ} \mathrm{C}$ on lag 0 were higher in males (1.21) than in females (1.16). For all-cause mortality, RaRRs for males at WBGT of $32.5^{\circ} \mathrm{C}$ on lags 0 and 1 were both 1.04 while those for females did not exist due to 
statistically insignificant RRs.

For different age groups, this work found that for all-cause mortality, the elderly was the only age group with statistically significant increase in RR on lags $0-1$ (both 1.04 ) at WBGT of $32.5^{\circ} \mathrm{C}$, with the highest RaRR on lag 0 (1.04) (Figures 2(f)). For emergency visits, the youth had the highest RaRR (1.87) on lag 0 at $\mathrm{WBGT}$ of $32.5^{\circ} \mathrm{C}$, followed by the elderly (1.52) (Figure 2(b)); while the reverse was true on lag 2 with the elderly having higher RaRR (1.38). For heat-related hospital visits, the highest RaRR (1.23) was observed among the elderly at WBGT of $32.5^{\circ} \mathrm{C}$ on lag 1.

In addition to RaRR, the frequency of expected heat warnings is also an important consideration when establishing a heat-warning system. Occurring frequency of days above certain threshold candidate is employed to examine whether the heat warnings issued on the basis of that specified threshold would be too frequent and too many. Figures 4 and 5 show the counts of periods of consecutive days exceeding the specified WBGT and temperature thresholds, respectively, in the entire island and different sub-regions between 2008 and 2017. There are five categories for periods of consecutive days, namely $1-5,6-10,11-15,16-20$, and $\geq 21$. One count represents one period, not one day, that met the specified criteria. For example, one count for 6-10 consecutive days denotes one period of 6-10 consecutive days occurring in that year. For both WBGT and temperature, applying region-specific thresholds (Figures 4(b) and 5(b), respectively) yielded fewer days above the specified thresholds, compared with the number of days obtained with the same threshold applied for the whole island (Figures 4(a) and 5(a), respectively). For the entire Taiwan, the top three years with the highest number of days above the specified threshold were 2014, 2016, and 2017, regardless of heat indicator used. For these years, there were more than 10 days above the WBGT threshold but fewer days above the temperature threshold. Among sub-regions (Figures 4(a) and 5(a)), North and Central Taiwan had more days above the same WBGT and temperature thresholds in all categories compared with South Taiwan. This phenomenon may be counter-intuitive at first sight, yet, attributable to heat accumulation by the basin location of their largest city in both North and Central Taiwan. 
To avoid too-frequent too-many heat warnings, region-specific thresholds are recommended. With the highest RaRR for emergency visits at WBGT threshold and the region-specific occurring frequency considered, the best threshold chosen were WBGT of $32.5^{\circ} \mathrm{C}, 34^{\circ} \mathrm{C}, 33.5^{\circ} \mathrm{C}, 32.5^{\circ} \mathrm{C}$, and $32^{\circ} \mathrm{C}$ for the entire, North, Central, South, and East Taiwan, respectively. Again, North and Central Taiwan had higher thresholds than South Taiwan, presumably due to the same aforementioned geographic location of their largest city.

\section{Discussion}

This work applies a modified GAM using RaRR to identify proper heat-warning thresholds. The advantage of using RaRR is that comparison on health risk increases can be made among different health outcomes across different categories for different heat indicators with different lag periods. The following discussion focuses on comparisons of RaRR, not RR, among different categories. Among different health outcomes, heat-related emergency visits had the highest RaRR and most prominent increasing trends at both WBGT and temperature thresholds with lags 0-2 for the whole Taiwan island and in most categories, followed by hospital visits, and all-cause mortality. Records of heat-related emergency visits represent direct and immediate health outcomes due to heat, while those of all-cause mortality represent the most general health outcome. Compared with those for the other two health outcomes, the increasing trends of RaRR for all-cause mortality at both WBGT and temperature thresholds were less obvious, with much fewer statistically significant RR (Tables A1-A4). With few exceptions, RaRR of emergency and hospital visits for all categories (sub-region, sex, and age) revealed rising trends with increasing WBGT and temperature thresholds. Moreover, abrupt increases were seen at the highest threshold candidates at lags 0-2 in most cases. The highest RaRR for the whole Taiwan island (1.44) was observed for heat-related emergency visits at WBGT of $32.5^{\circ} \mathrm{C}$ with $\operatorname{lag} 0$. All RaRR for hospital visits at WBGT thresholds were less than 1.25, lower than those for emergency visits; while those for all-cause mortality were even lower than 1.04 . 
A warning system with the threshold identified using all-cause mortality aims at reducing overall mortality, while those with thresholds determined using emergency and hospital visits target at reducing morbidity related to human well-being and work productivity (27-33). Compared with that between heat and mortality, the relationship of heat with morbidity is less documented as reviewed by Li et al. (29). However, morbidity occurs before mortality; hence, selecting heat-warning threshold on the basis of heat-related emergency or hospital visits is recommended for protecting both health and well-being of the general public under climate change. In view of increasing occurring frequency of extreme events in recent years, periodical evaluations should be conducted to update the chosen threshold.

The lack of a systematic methodology for selecting a proper threshold poses challenge to the authorities in establishing an effective heat warning system, which accompanied with responsive actions is viewed as the critical health adaptation strategy needed in all countries (34). Particularly, in tropical and subtropical countries where inhabitants deem themselves already adapted to hot climate, which is not true as shown in various studies $(7,8,11,22)$, heat-related health risks under climate change are given insufficient attention and heat warnings may even be ignored. Specifically, the lowand middle-income countries disproportionately affected by climate change (3) and located in tropical/subtropical areas are in urgent need for a heat warning system. This study presents a systematic approach to selecting the appropriate heat-warning thresholds, taking into consideration substantial enhancement of health risks on lags 0 to 2 . The modified GAM has rare-event interference removed and can accommodate at-risk populations of different sizes. For demonstration, Taiwan's meteorological and health data of 18 years were analyzed. Only data of warm seasons were included, thus eliminating the need to consider seasonal effect. The results obtained clearly show the feasibility and flexibility of the proposed approach which could be applied to other countries. Selecting heatwarning thresholds according to records of heat-related emergency visits is thus recommended. 
Nevertheless, the small counts in emergency visits cause problem to statistical evaluation. To overcome the problem, this work further modified a recently revised GAM (11) to deal with smallsized populations. The present method successfully obtained appropriate threshold candidates for all sub-regions in Taiwan having different population sizes and areas, with the exception of East Taiwan. Compared with other sub-regions, East Taiwan has a smaller population and much lower population density (Table 1), with very few counts in the three health outcomes (Table 2). As a result, East Taiwan had few RRs with statistical significance and showed inconsistent trends of increase in RaRR. Therefore, caution should be taken when applying the present method in cities and countries with atrisk populations of small sizes.

The candidate with the highest RaRR not occurring too frequently is potentially the best threshold. RaRR emphasizes the substantial enhancement of health risks compared with that of a reference to ensure that the chosen threshold is at the starting point of substantial health risks rather than just outside the human comfort zone. The health risks above this threshold can be reduced through prompt issuance of heat warning accompanied with effective responsive measures. With occurring frequency above the specified threshold assessed, a proper threshold of a heat warning system can be selected according to the discretion of the authority. Policy considerations may involve reducing heat-related morbidity or mortality, expected frequency of warnings issued, vulnerable populations targeted, and resources required for the corresponding intervention plans, which are beyond the scope of this manuscript. Nevertheless, the proposed approach provides policy-makers a systematic scientific tool for establishing a heat warning system with any health outcome records available as the key element.

Attempts have been made to identify thresholds in different countries for heat-health intervention measures for the general public. For example, in the US, Petitti et al. (12) attempted to determine multiple trigger points for activating heat-health intervention measures with multiple health outcomes. In Brisbane, Australia, Tong et al. (35) assessed the RR of daily mortality and emergency hospital admissions of previous heatwave events and proposed a tiered heat warning system according to health 
risks under a heatwave. In South Korea, Kang et al. (36) also put forward a mortality risk-based method considering lag-cumulative heatwave-related mortality risk at district levels, and pooled the results with meta-analysis to define heat wave. The current work used both morbidity and mortality records to assess appropriate heat-warning thresholds for different sub-regions with at-risk populations of different sizes, further demonstrating the flexibility and applicability of the present method.

Thresholds for heat-health impacts in Taiwan have been assessed with different heat indicators, mostly with temperature. The optimal temperature proposed for the three biggest cities in Taiwan range from $31.2^{\circ} \mathrm{C}$ to $33.4^{\circ} \mathrm{C}(37,38)$. Furthermore, studies have shown that the impacts of heat indicators on all-cause mortality and all-cause outpatient visits started to emerge in the temperature range of 25$30^{\circ} \mathrm{C}$ in Taiwan $(21,39)$. A recent study also attempted to identify the temperature with the lowest health risks (40). Again, these works focused on determining the starting points of heat-health impacts outside the human comfort zones rather than thresholds of a heat warning system. Our previous work had identified the heat-warning threshold of WBGT at $33^{\circ} \mathrm{C}$ for the whole Taiwan island without considering the lag effect (11). On the basis of our prior research, this work further modified the statistical model with the lag effect for two days taken into consideration, and evaluated systematically RaRRs of different threshold candidates, as another alternative approach to the comparison of "difference" presented earlier (11). RaRR may be mathematically and conceptually superior than the earlier "difference" comparison and provides a more systematic assessment on RR comparisons. Thus, using RaRR to identify thresholds for a heat warning system is recommended.

Whether WBGT or temperature is more suitable for heat-health warnings can also be evaluated with RaRR. At both WBGT and temperature thresholds, RaRR of heat-related emergency and hospital visits for the whole Taiwan island showed similar increasing patterns. Nevertheless, for the immediate heat-health outcome, i.e., heat-related emergency visits, substantially higher RaRR for different sex, age and sub-regions, except Central Taiwan, were observed at WBGT thresholds than at temperature ones. Moreover, only minor differences in RaRR were observed for emergency and hospital visits 
among different sex and age groups at temperature thresholds compared with WBGT ones. Taken together, these results revealed that WBGT is a more sensitive heat-health indicator than temperature, especially for vulnerable populations. Recent studies have demonstrated that WBGT is a better heatstress indicator for the general public, compared with temperature or apparent temperature $(11,21,41)$. The Hong Kong government has begun using a modified WBGT as one of their heat indices (41). Japan and Australia also present WBGT as one of the heat indicators for the general public $(42,43)$. Thus, WBGT should be considered a proper heat indicator for a heat-health warning system. Issuing heat warnings on the basis of WBGT would protect public health against heat-related health hazards.

In general, for the whole Taiwan island, the highest RaRR with WBGT shifted from lag 0 in emergency visits to lag 1 in hospital visits, especially for the most vulnerable children (0-14 years) and elderly ( $\geq 65$ years) populations, and also to lag 1 in all-cause mortality. It is expected because heatrelated emergency visit is the most direct health outcome. Longer lag periods of heat-health relationship have been evaluated up to 25 or 30 days; nevertheless, the most significant morbidity and mortality impacts was found to occur in the first two days immediately after exposure to heat $(29,40$, 44). A recent study analyzed emergency ambulance calls on hourly basis in China and found that hot temperature was positively associated with all-cause and cardiovascular diseases at lags of 0-30 and 0-9 hours, respectively (45), consistent with the present findings. Our results clearly showed lag-day shifts among different health outcomes, demonstrating that the modified model can identify heatwarning thresholds with lag effects of 2 days and Eq. (5) is applicable to analysis on longer lag period.

The present findings also showed varied patterns in different sub-regions in Taiwan, an island with geographically distinct regional features. Previous studies have demonstrated spatial variation of heat-related health impacts $(29,36,44)$. Hence, it is important to identify area-specific thresholds to effectively reduce heat-health risks of that area.

As for health impacts with WBGT on different sex groups, our analysis showed mixed results of 
either higher heat-health risks for males or females in morbidity or mortality, similar to those presented in the literature $(44,46-48)$. For example, a study found that males were more affected than females in heat-related illness (29). It was speculated that males may suffer more from heat partly due to their participation in more outdoor activities (29). However, other studies found higher heat-health impacts in either sex in different cities $(44,47-48)$. A review study concluded that heat-related health impacts could be higher for males or females for different health outcomes (29). Other socio-demographic factors may play a role such as education level, marital status, and number of household occupants (47).

For heat and mortality/morbidity in different age groups, most studies found the elderly to be the most vulnerable group, followed by the youth $(6,9,27,29,36,47,49,50)$. Our results showed that children had the highest RaRR for emergency visits on lag 0 (1.87) while the elderly had the highest RaRR for all-cause mortality on lag 0 (1.04), the highest RaRR for hospital visits on lag 1 (1.23), and the highest RaRR for emergency visits on lag 2 (1.38). Due consideration given to different responses and lag days of these vulnerable populations is crucial when designing responsive actions following the heat-health warning to reduce their risks. With RaRR, health risks of different threshold candidates among different sub-groups can be compared because they are against the same reference. The above comparisons demonstrate the merits of the present method.

Furthermore, it should be noted that RaRR for heat-related hospital visits of those aged 15-64 with WBGT (1.17) is close to that of the youth (1.18) but higher than that of the elderly (1.13) on lag 0 . The high RaRR in this age group, of mostly working adults, may be related to their higher chances of exposure to high heat under the sun while engaged in outdoor activities (29). These findings emphasized variations in vulnerability of sub-populations due to difference in their exposure to high heat. Therefore, specific responsive actions following a warning system should be deliberately designed for different sub-populations to reduce their heat exposures for more effective reduction of 
heat-health risks.

There are two limitations in this study. First, although Taiwan does not have an official heat warning system, the government did send out alert in the daily weather report if the forecasted temperature is high, particularly above $37^{\circ} \mathrm{C}$ in the past 5-6 years. The dataset analyzed covers 18 years; and the alert issued in recent years may change people's behaviors and reduce the number of recent cases in the health database. Secondly, adaptation measures taken on hot days in Taiwan were not taken into account. Taiwan has 93\% prevalence of air-conditioning (51). Almost all office buildings during daytime and most households in the evening turn on air-conditioning in summer time. These adaptation measures may affect the analysis, giving statistically insignificant results even under high heat-stress condition. Despite of these limitations which would bias the results towards null, the present findings did show statistically significant RRs in most of the assessments, demonstrating significant heat-health impacts.

\section{Conclusions}

In response to the call from UN for partnership for all to meet the third Sustainable Development Goal in reducing health risks due to rapid climate change, this study presents a modified approach to assisting central and local governments worldwide in identifying proper heat-warning threshold according to local health evidences. Although the proposed approach can be applied with any heat indicator, WBGT is recommended as the best for a heat warning system. WBGT has been used for six decades as an indicator for preventing heat-stress-related health impacts in workplace. New thresholds for WBGT in a heat-health warning system are needed to protect vulnerable populations in the general public, such as those aged $0-14$ and $\geq 65$ years. The current results showed that children had the highest emergency visits on lag 0 while the elderly had the highest mortality on lag 0 , the highest hospital visits on lag 1, and the highest emergency visits on lag 2 . With the present method, proper thresholds for heat-warning systems can be identified so that excess health risks can be reduced with advance 
warnings. The proposed approach can also facilitate other countries in establishing WBGT-based heathealth warning systems for the general public.

This refined approach assessed heat-health relationships of emergency/hospital visits and mortality using a modified GAM with lag effect of 0-2 days taken into account, compared RR of different threshold candidates with that of a reference using RaRR, expanded statistical models considering at-risk populations of different sizes, and evaluated region-specific historical occurrence frequency. The novel RaRR allows comparison of health risks across different categories, providing a solid scientific basis for threshold selection. Results showed that heat-related emergency visit is the most sensitive heat-related health record and should thus be employed, if available, to select heatwarning threshold. The highest RaRR with WBGT as heat indicator for the whole Taiwan island was observed to shift from lag 0 in emergency visits to lag 1 in hospital visits especially for the most vulnerable youth and elderly, and also to lag 1 in all-cause mortality. Thus, lag period of at least one day should be taken into account when selecting the proper threshold. With RaRR of heat-related emergency visits and occurring frequency considered, the recommended WBGT thresholds are $32.5^{\circ} \mathrm{C}$, $34^{\circ} \mathrm{C}, 33.5^{\circ} \mathrm{C}, 32.5^{\circ} \mathrm{C}$, and $32^{\circ} \mathrm{C}$ for whole, North, Central, South, and East Taiwan, respectively. In view of the spatial variations of heat-health impacts, threshold identification should be conducted for specific cities/regions. In summary, using health records in Taiwan for demonstration, this work presents a systematic scientific tool for selecting a proper threshold as the basis of an effective warning system for better heat-stress adaptation to reduce health risks of climate change.

\section{List of abbreviations:}

GAM: generalized additive model; ICD: International Classification of Diseases; RR: risk ratio; RaRR: reference-adjusted risk ratio; WBGT: wet-bulb globe temperature 


\section{Supporting information:}

File name: Additional file

File format: .pdf

Title of data:

Figure A1 Taiwan island divided into sub-regions of North, Central, South, and East Taiwan

Table A1 Risk ratios of (a) heat-related emergency visits, (b) heat-related hospital visits, and (c) allcause mortality at different WBGT threshold candidates for different sex and age groups

Table A2 Risk ratios of (a) heat-related emergency visits, (b) heat-related hospital visits, and (c) allcause mortality at different WBGT threshold candidates for different sub-regions

Table A3 Risk ratios of (a) heat-related emergency visits, (b) heat-related hospital visits, and (c) allcause mortality at different temperature threshold candidates for different sex and age groups

Table A4 Risk ratios of (a) heat-related emergency visits, (b) heat-related hospital visits, and (c) allcause mortality at different temperature threshold candidates for different sub-regions

\section{Declarations}

\section{Ethics approval and consent to participate}

This study was reviewed and approved by the Internal Review Board of Academia Sinica, IRB No. AS-IRB-BM-18030.

\section{Consent for publication}

Not applicable.

\section{Availability of data and materials}

The health records contain sensitive individual-level information which is not publicly available. It can be made available to researchers after approval of a formal application to the Health and Welfare 
Data Science Center of the Ministry of Health and Welfare. The meteorological data used to calculate WBGT can be obtained with a formal application to the Central Weather Bureau. The air pollutant data can be obtained with a formal application to the Taiwan Environmental Protection Administration.

\section{Competing interests}

The authors declare they have no actual or potential competing financial interests.

\section{Funding}

Full funding sources are listed in the Acknowledgment.

\section{Authors' contributions}

SCCL conceived the original idea, obtained funding, provided input to data analyses and interpretation, wrote the first draft of the manuscript, and supervised the work. JCJY conducted data analysis and provided input to data interpretation and graphic presentations. JSH modified the statistical model and participated in data analyses and interpretation. All authors were involved in revising the manuscript.

\section{Acknowledgements}

We would like to acknowledge the in-house funding support from the Research Center for Environmental Changes of Academia Sinica, the Academia Sinica thematic project "Integrated Multisource and High-resolution Heat Wave Vulnerability Assessment of Taiwan (AS-104-SS-A02)", and Ministry of Science and Technology project 108-2621-M-001-004. We also thank the Health and Welfare Data Science Center of the Ministry of Health and Welfare, Taiwan Environmental Protection Administration, and Taiwan Central Weather Bureau for providing data. The contents of this paper are solely the responsibility of the authors and do not represent the official views of the aforementioned institutes and funding agencies. 


\section{References}

1. United Nation Environmental Programme (UNEP). 2020. Available from: https://www.unenvironment.org/explore-topics/climate-change/facts-about-climate-emergency. accessed 26 January, 2021.

2. IPCC (Intergovernmental Panel on Climate Change). Climate change 2014: Impacts, adaptation, and vulnerability. Part A: Global and sectoral aspects Contribution of working group II to the fifth assessment report of the Intergovernmental Panel on Climate Change. (Field CB, V.R. Barros, D.J. Dokken, K.J. Mach, M.D. Mastrandrea, T.E. Bilir, M. Chatterjee, K.L. Ebi, Y.O. Estrada, R.C. Genova, B. Girma, E.S. Kissel, A.N. Levy, S. MacCracken, P.R. Mastrandrea, and L.L. White, ed). Cambridge University Press, Cambridge, United Kingdom and New York, NY, USA, 1132.

3. Watts N, Adger WN, Ayeb-Karlsson S, Bai Y, Byass P, Campbell-Lendrum D, et al. The Lancet Countdown: tracking progress on health and climate change. The Lancet. 2017;389(10074):115164. https://doi:10.1016/s0140-6736(16)32124-9.

4. World Meteorological Organization (WMO). 2020. Available from: https://public.wmo.int/en/media/news/2020-closes-decade-of-exceptional-heat. accessed 26 January, 2021.

5. UN (United Nations). Sustainable Development Goals (SDGs). 2018. Available: https://www.un.org/sustainabledevelopment/. accessed 26 January, 2021.

6. Le Tertre A, Lefranc A, Eilstein D, Declercq C, Medina S, Blanchard M, et al. Impact of the 2003 heatwave on all-cause mortality in 9 French cities. Epidemiology. 2006;17(1):75-9. https://doi:10.1097/01.ede.0000187650.36636.1f.

7. Ghumman U, Horney J. Characterizing the Impact of Extreme Heat on Mortality, Karachi, Pakistan, June 2015. Prehospital Disaster Med. 2016;31(3):263-6. 
https://doi:10.1017/s1049023x16000273.

8. Sarath Chandran MA, Subba Rao AVM, Sandeep VM, Pramod VP, Pani P, Rao VUM, et al. Indian summer heat wave of 2015: a biometeorological analysis using half hourly automatic weather station data with special reference to Andhra Pradesh. Int J Biometeorol. 2017;61(6):1063-72. https://doi:10.1007/s00484-016-1286-9.

9. Changnon SA, Kunkel KE, Reinke BC. Impacts and responses to the 1995 heat wave: A call to action. Bulletin of the American Meteorological Society. 1996;77(7):1497506.https://doi.org/10.1175/1520-0477(1996)077<1497:IARTTH>2.0.CO;2.

10. Semenza JC, Rubin CH, Falter KH, Selanikio JD, Flanders WD, Howe HL, et al. Heat-related deaths during the July 1995 heat wave in Chicago. New England Journal of Medicine. 1996;335(2):84-90. https://doi:10.1056/nejm199607113350203.

11. Cheng Y-T, Lung S-CC, Hwang J-S. New approach to identifying proper thresholds for a heat warning system using health risk increments. Environmental Research. 2019;170:282-92. https://doi.org/10.1016/j.envres.2018.12.059.

12. Petitti DB, Hondula DM, Yang S, Harlan SL, Chowell G. Multiple Trigger Points for Quantifying Heat-Health Impacts: New Evidence from a Hot Climate. Environmental Health Perspectives. 2016;124(2):176-83. https://doi:10.1289/ehp.1409119.

13. Bernard TE. Thermal stress. In Fundamentals of Industrial Hygene:Chapter 12, Edition 6th (Plog BA, Quinlan P, eds): Itasca, Ill. . National Safety Council. 2012:335-61.

14. Błażejczyk K BJ, Błażejczyk A. Heat stress and occupational health and safety - spatial and temporal differentiation. Miscellanea Geographica - Regional Studies on Development. 2014.

15. Brode P, Fiala D, Lemke B, Kjellstrom T. Estimated work ability in warm outdoor environments depends on the chosen heat stress assessment metric. Int J Biometeorol. 2018;62(3):331-45. https://doi:10.1007/s00484-017-1346-9.

16. ISO (International Standards Organization). 2017. Ergonomics of the thermal environment -- 
assessment of heat stress using the WBGT (wet bulb globe temperature) index. Available: https://www.iso.org/standard/67188.html. accessed 26 January, 2021.

17. Spector JT, Sheffield PE. Re-evaluating Occupational Heat Stress in a Changing Climate. Ann Occup Hyg. 2014;58(8):936-42. https://doi:10.1093/annhyg/meu073.

18. Yaglou CP MD. Prevention of heat casualties at marine corps training centers. Armed Services Technical Information Agency Document Service Center AD099920. 1956.

19. Hyatt OM, Lemke B, Kjellstrom T. Regional maps of occupational heat exposure: past, present, and potential future. Glob Health Action. 2010;3:10. https://doi:10.3402/gha.v3i0.5715.

20. Kakamu T, Wada K, Smith DR, Endo S, Fukushima T. Preventing heat illness in the anticipated hot climate of the Tokyo 2020 Summer Olympic Games. Environ Health Prev. 2017;22(1). https://doi:10.1186/s12199-017-0675-y.

21. Lin Y-K, Chang C-K, Li M-H, Wu Y-C, Wang Y-C. High-temperature indices associated with mortality and outpatient visits: Characterizing the association with elevated temperature. Sci Total Environ. 2012;427:41-9. https://doi:10.1016/j.scitotenv.2012.04.039.

22. Sung TI, Wu PC, Lung SC, Lin CY, Chen MJ, Su HJ. Relationship between heat index and mortality of 6 major cities in Taiwan. Sci Total Environ. 2013;442:275-81. https://doi:10.1016/j.scitotenv.2012.09.068.

23. Yamamoto S, Iwamoto M, Inoue M, Harada N. Evaluation of the effect of heat exposure on the autonomic nervous system by heart rate variability and urinary catecholamines. J Occup Health. 2007;49(3):199-204.

24. Liljegren JC CR, Lawday P, Tschopp S, Sharp R. Modeling the wet bulb globe temperature using standard meteorological measurements. J Occup Environ Hyg. 2008; 5:645-55. https://doi.org/10.1080/15459620802310770.

25. Ye X, Wolff R, Yu W, Vaneckova P, Pan X, Tong S. Ambient Temperature and Morbidity: A Review of Epidemiological Evidence. Environmental Health Perspectives. 2012;120(1):19-28. 
https://doi:10.1289/ehp.1003198.

26. Pan WH, Li LA, Tsai MJ. TEMPERATURE EXTREMES AND MORTALITY FROM CORONARY HEART-DISEASE AND CEREBRAL INFARCTION IN ELDERLY CHINESE. Lancet. 1995;345(8946):353-5. https://doi:10.1016/s0140-6736(95)90341-0.

27. Astrom DO, Forsberg B, Rocklov J. Heat wave impact on morbidity and mortality in the elderly population: A review of recent studies. Maturitas. 2011;69(2):99-105. https://doi.org/10.1016/j.maturitas.2011.03.008.

28. Knowlton K, Rotkin-Ellman M, King G, Margolis HG, Smith D, Solomon G, et al. The 2006 California Heat Wave: Impacts on Hospitalizations and Emergency Department Visits. Environmental Health Perspectives. 2009;117(1):61-7. https://doi:10.1289/ehp.11594.

29. Li M, Gu S, Bi P, Yang J, Liu Q. Heat Waves and Morbidity: Current Knowledge and Further Direction-A Comprehensive Literature Review. International Journal of Environmental Research and Public Health. 2015;12(5):5256-83. https://doi:10.3390/ijerph120505256.

30. Mastrangelo G, Fedeli U, Visentin C, Milan G, Fadda E, Spolaore P. Pattern and determinants of hospitalization during heat waves: an ecologic study. BMC Public Health. 2007;7. https://doi:10.1186/1471-2458-7-200.

31. Semenza JC, McCullough JE, Flanders WD, McGeehin MA, Lumpkin JR. Excess hospital admissions during the July 1995 heat wave in Chicago. American Journal of Preventive Medicine. 1999;16(4):269-77. https://doi:10.1016/s0749-3797(99)00025-2.

32. Sheridan SC, Lin S. Assessing Variability in the Impacts of Heat on Health Outcomes in New York City Over Time, Season, and Heat-Wave Duration. Ecohealth. 2014;11(4):512-25. https://doi:10.1007/s10393-014-0970-7.

33. Xia Y, Li Y, Guan D, Tinoco DM, Xia J, Yan Z, et al. Assessment of the economic impacts of heat waves: A case study of Nanjing, China. Journal of Cleaner Production. 2018;171:811-9. https://doi:10.1016/j.jclepro.2017.10.069. 
34. Smith et al KRS, A. Woodward, D. Campbell-Lendrum, D.D. Chadee, Y. Honda, Q. Liu, et al. Human health: impacts, adaptation, and co-benefits. B Field, VR Barros, DJ Dokken, KJ Mach, MD Mastrandrea, TE Bilir, M Chatterjee, KL Ebi, YO Estrada, RC Genova, B Girma, ES Kissel, AN Levy, S MacCracken, PR Mastrandrea, LL White (Eds), Climate Change 2014: Impacts, Adaptation, and Vulnerability 2014: 709-54.

35. Tong S, Wang XY, FitzGerald G, McRae D, Neville G, Tippett V, et al. Development of health risk-based metrics for defining a heatwave: a time series study in Brisbane, Australia. BMC Public Health. 2014;14. https://doi:10.1186/1471-2458-14-435.

36. Kang C, Park C, Lee W, Pehlivan N, Choi M, Jang J, et al. Heatwave-Related Mortality Risk and the Risk-Based Definition of Heat Wave in South Korea: A Nationwide Time-Series Study for 2011-2017. International Journal of Environmental Research and Public Health 2020;17(16):5720. https://doi:10.3390/ijerph17165720.

37. Honda Y, Kabuto M, Ono M, Uchiyama I. Determination of optimum daily maximum temperature using climate data. Environ Health Prev. 2007;12(5):209-16. https://doi:10.1265/ehpm.12.209.

38. Honda Y, Kondo M, McGregor G, Kim H, Guo YL, Hijioka Y, et al. Heat-related mortality risk model for climate change impact projection. Environ Health Prev. 2014;19(1):56-63. https://doi:10.1007/s12199-013-0354-6.

39. Lin Y-K, Ho T-J, Wang Y-C. Mortality risk associated with temperature and prolonged temperature extremes in elderly populations in Taiwan. Environmental Research. 2011;111(8):1156-63. https://doi:10.1016/j.envres.2011.06.008.

40. Lin Y-K, Sung F-C, Honda Y, Chen Y-J, Wang Y-C. Comparative assessments of mortality from and morbidity of circulatory diseases in association with extreme temperatures. Sci Total Environ. 2020;723:138012. https://doi:10.1016/j.scitotenv.2020.138012.

41. Lee KL, Chan YH, Lee TC, Goggins WB, Chan EYY. The development of the Hong Kong Heat Index for enhancing the heat stress information service of the Hong Kong Observatory. Int $\mathrm{J}$ 
Biometeorol. 2016;60(7):1029-39. https://doi:10.1007/s00484-015-1094-7.

42. Japanese Ministry of the Environment. 2018. Homepage: Heat illness prevention information. Available: http://www.wbgt.env.go.jp/en/. accessed 26 January, 2021.

43. Australian Government - Bureau of Meteorology. 2018. Homepage: Heatwave Service for Australia. Available: http://www.bom.gov.au/australia/heatwave/index.shtml. accessed 26 January, 2021.

44. Arbuthnott K, Hajat S, Heaviside C, Vardoulakis S. Years of life lost and mortality due to heat and cold in the three largest English cities. Environment International. 2020;144:105966. https://doi.org/10.1016/j.envint.2020.105966.

45. Cui Y, Ai S, Liu Y, Qian Z, Wang C, Sun J, et al. Hourly associations between ambient temperature and emergency ambulance calls in one central Chinese city: Call for an immediate emergency plan. Sci Total Environ. 2020;711:135046. https://doi:10.1016/j.scitotenv.2019.135046.

46. Bai L, Ding G, Gu S, Bi P, Su B, Qin D, et al. The effects of summer temperature and heat waves on heat-related illness in a coastal city of China, 2011-2013. Environmental Research. 2014;132:212-9. https://doi.org/10.1016/j.envres.2014.04.002.

47. Ellena M, Ballester J, Mercogliano P, Ferracin E, Barbato G, Costa G, et al. Social inequalities in heat-attributable mortality in the city of Turin, northwest of Italy: a time series analysis from 1982 to 2018. Environmental Health. 2020;19(1).

48. Pyrgou A, Santamouris M. Probability Risk of Heat- and Cold-Related Mortality to Temperature, Gender, and Age Using GAM Regression Analysis. Climate. 2020;8(3):40. https://doi:10.3390/cli8030040.

49. Xing Q, Sun Z, Tao Y, Zhang X, Miao S, Zheng C, et al. Impacts of urbanization on the temperature-cardiovascular mortality relationship in Beijing, China. Environmental Research. 2020;191:110234. https://doi:10.1016/j.envres.2020.110234.

50. Xu Z, Etzel RA, Su H, Huang C, Guo Y, Tong S. Impact of ambient temperature on children's 
health: A systematic review. Environmental Research. 2012;117:120-31. https://doi:10.1016/j.envres.2012.07.002.

51. Taiwan National Development Council. 2018. Government website open information announcement. Available: https://data.gov.tw/en/. accessed 26 January, 2021. 
Table 2 Summary of warm-season (a) health and (b) environment data analyzed

(May to October, 2000-2017)

(a)

\begin{tabular}{|c|c|c|c|c|c|c|c|c|c|c|c|c|}
\hline \multirow{3}{*}{ Category } & \multicolumn{4}{|c|}{ Daily emergency visits } & \multicolumn{3}{|c|}{ Daily hospital visits } & & \multicolumn{4}{|c|}{ Daily all-cause mortality } \\
\hline & \multicolumn{4}{|c|}{$\left(n^{b}\right)$} & \multicolumn{4}{|c|}{$\left(n^{b}\right)$} & \multicolumn{4}{|c|}{$(\mathrm{n}=1840)$} \\
\hline & Mean & $\mathrm{SD}$ & Min & Max & Mean & $\mathrm{SD}$ & Min & Max & Mean & $\mathrm{SD}$ & Min & Max \\
\hline Whole Taiwan island & 8 & 9 & 0 & 73 & 222 & 266 & 1 & 1533 & 357 & 56 & 187 & 510 \\
\hline \multicolumn{13}{|l|}{ Sex } \\
\hline Female & 2 & 3 & 0 & 26 & 126 & 155 & 0 & 855 & 145 & 26 & 67 & 230 \\
\hline Male & 6 & 6 & 0 & 45 & 93 & 109 & 0 & 673 & 212 & 33 & 113 & 291 \\
\hline \multicolumn{13}{|l|}{ Age (years) } \\
\hline $0-14$ & 1 & 1 & 0 & 7 & 9 & 9 & 0 & 63 & 3 & 2 & 0 & 10 \\
\hline $15-64$ & 6 & 7 & 0 & 51 & 189 & 231 & 0 & 1351 & 94 & 16 & 42 & 140 \\
\hline$\geq 65$ & 1 & 2 & 0 & 19 & 23 & 28 & 0 & 176 & 260 & 44 & 131 & 390 \\
\hline
\end{tabular}

Sub-region 


\begin{tabular}{|c|c|c|c|c|c|c|c|c|c|c|c|c|}
\hline \multirow[t]{2}{*}{ Category } & \multicolumn{4}{|c|}{$\left(n^{b}\right)$} & \multicolumn{4}{|c|}{$\left(n^{b}\right)$} & \multicolumn{4}{|c|}{$(\mathrm{n}=1840)$} \\
\hline & Mean & SD & Min & Max & Mean & $\mathrm{SD}$ & Min & Max & Mean & $\mathrm{SD}$ & Min & Max \\
\hline North Taiwan & 3 & 4 & 0 & 41 & 117 & 149 & 0 & 917 & 148 & 19 & 93 & 218 \\
\hline Central Taiwan & 2 & 2 & 0 & 24 & 81 & 94 & 0 & 510 & 67 & 16 & 15 & 113 \\
\hline South Taiwan & 2 & 3 & 0 & 23 & 17 & 20 & 0 & 152 & 121 & 30 & 25 & 182 \\
\hline East Taiwan $^{\mathrm{c}}$ & 1 & 2 & 0 & 15 & 9 & 11 & 0 & 67 & 21 & 5 & 7 & 40 \\
\hline
\end{tabular}

(b)

Daily maximum WBGT $\left({ }^{\circ} \mathrm{C}\right) \quad$ Daily maximum temperature $\left({ }^{\circ} \mathrm{C}\right) \quad$ Daily mean $\mathrm{PM} 2.5\left(\mu \mathrm{g} / \mathrm{m}^{3}\right)$

\begin{tabular}{|c|c|c|c|c|c|c|c|c|c|c|c|c|}
\hline \multirow[t]{2}{*}{ Category } & \multicolumn{4}{|c|}{$\left(n^{d}\right)$} & \multicolumn{4}{|c|}{$\left(n^{b}\right)$} & \multicolumn{4}{|c|}{$\left(n^{\mathrm{e}}\right)$} \\
\hline & Mean & $\mathrm{SD}$ & Min & Max & Mean & SD & Min & Max & Mean & $\mathrm{SD}$ & Min & $\operatorname{Max}$ \\
\hline Whole Taiwan island & 29.7 & 2.4 & 19.5 & 33.6 & 30.7 & 2.2 & 21.1 & 34.8 & 25.4 & 11.1 & 5.9 & 92.0 \\
\hline North Taiwan & 29.4 & 3.3 & 16.3 & 35.5 & 30.6 & 3.2 & 18.3 & 37.1 & 22.1 & 10.7 & 2.1 & 106.5 \\
\hline Central Taiwan & 29.9 & 2.3 & 19.7 & 38.1 & 31.4 & 2.2 & 20.4 & 39.7 & 27.8 & 14.9 & 5.0 & 139.7 \\
\hline South Taiwan & 30.0 & 1.9 & 21.1 & 34.0 & 31.3 & 1.8 & 22.2 & 34.9 & 28.1 & 15.6 & 5.9 & 207.1 \\
\hline
\end{tabular}




\begin{tabular}{|c|c|c|c|c|c|c|c|c|c|c|c|c|}
\hline \multirow[t]{2}{*}{ Category } & \multicolumn{4}{|c|}{$\left(n^{d}\right)$} & \multicolumn{4}{|c|}{$\left(n^{b}\right)$} & \multicolumn{4}{|c|}{$\left(n^{\mathrm{e}}\right)$} \\
\hline & Mean & $\mathrm{SD}$ & Min & Max & Mean & $\mathrm{SD}$ & Min & Max & Mean & $\mathrm{SD}$ & Min & $\operatorname{Max}$ \\
\hline East Taiwan $^{\mathrm{b}}$ & 29.7 & 2.6 & 19.0 & 33.8 & 30.3 & 2.2 & 21.4 & 34.7 & 15.0 & 7.6 & 4.5 & 72.7 \\
\hline
\end{tabular}

a: Analysis for all-cause mortality was for 2008-2017 only due to locations of death not specified for 2000-2007

b: $\mathrm{n}=3312$ for North, Central and South Taiwan, $\mathrm{n}=2392$ for East Taiwan

c: Analysis for East Taiwan was for 2005-2017 only due to no $\mathrm{PM}_{2.5}$ measurements for 2000-2004

d: $\mathrm{n}=3312$ for North and South Taiwan, $\mathrm{n}=3310$ for Central Taiwan, $\mathrm{n}=2392$ for East Taiwan

$\mathrm{e}: \mathrm{n}=3312,3207,3275,3243$ and 2392 for the whole Taiwan, North, Central, South, and East Taiwan, respectively.

SD: standard deviation; Min: minimum; Max: Maximum 
Table 3 Risk ratios at different (a) WBGT and (b) temperature threshold candidates for whole Taiwan island

(a) WBGT

Risk ratios $(\mathrm{RR})(\mathbf{9 5 \%} \mathrm{CI})^{\mathrm{a}}$

\begin{tabular}{|c|c|c|c|c|c|}
\hline Threshold $\left({ }^{\circ} \mathrm{C}\right)$ & 30 & 31 & 31.5 & 32 & 32.5 \\
\hline \multicolumn{6}{|c|}{ Heat-related emergency visits } \\
\hline Lag 0 & $1.26^{* * *}(1.25,1.28)$ & $1.32^{* * *}(1.30,1.35)$ & $1.37^{* * *}(1.34,1.40)$ & $1.48^{* * *}(1.43,1.52)$ & $1.82^{* * *}(1.69,1.97)$ \\
\hline Lag 1 & $1.09^{* * *}(1.07,1.10)$ & $1.11^{* * *}(1.09,1.13)$ & $1.13^{* * *}(1.11,1.16)$ & $1.19^{* * *}(1.14,1.23)$ & $1.31^{* * *}(1.20,1.43)$ \\
\hline Lag 2 & $1.00 \quad(0.99,1.01)$ & $1.02^{*}(1.00,1.04)$ & $1.05^{* * *}(1.03,1.07)$ & $1.08^{* * *}(1.05,1.12)$ & $1.14^{* * *}(1.05,1.24)$ \\
\hline \multicolumn{6}{|c|}{ Heat-related hospital visits } \\
\hline Lag 0 & $1.08^{* * *}(1.08,1.08)$ & $1.09^{* * *}(1.09,1.09)$ & $1.10^{* * *}(1.10,1.11)$ & $1.14^{* * *}(1.13,1.15)$ & $1.27^{* * *}(1.26,1.29)$ \\
\hline Lag 1 & $1.04^{* * * *}(1.04,1.05)$ & $1.07^{* * *}(1.06,1.07)$ & $1.09^{* * *}(1.09,1.10)$ & $1.13^{* * *}(1.12,1.13)$ & $1.23^{* * * *}(1.21,1.25)$ \\
\hline Lag 2 & $1.05^{* * *}(1.05,1.05)$ & $1.07^{* * *}(1.06,1.07)$ & $1.08^{* * *}(1.08,1.09)$ & $1.11^{* * *}(1.10,1.12)$ & $1.17^{* * * *}(1.15,1.19)$ \\
\hline \multicolumn{6}{|c|}{ All-cause mortality } \\
\hline Lag 0 & $1.00^{* * * *}(1.00,1.01)$ & $1.00^{*}(1.00,1.01)$ & $1.01^{*}(1.00,1.01)$ & $1.01^{* *}(1.00,1.02)$ & $1.03^{* *}(1.01,1.05)$ \\
\hline Lag 1 & $1.00^{* *}(1.00,1.01)$ & $1.01^{* * *}(1.00,1.01)$ & $1.01^{* * *}(1.01,1.02)$ & $1.02^{* * *}(1.01,1.03)$ & $1.04^{* *}(1.01,1.06)$ \\
\hline Lag 2 & $1.00 \quad(1.00,1.00)$ & $1.00^{*}(1.00,1.01)$ & $1.01^{*}(1.00,1.01)$ & $1.01 \quad(1.00,1.02)$ & $1.02(1.00,1.04)$ \\
\hline
\end{tabular}




\section{$\operatorname{RR}(\mathbf{9 5 \%} \mathrm{CI})^{\text {a }}$}

\begin{tabular}{|c|c|c|c|c|c|c|}
\hline Threshold $\left({ }^{\circ} \mathrm{C}\right)$ & 30 & 31 & 32 & 32.5 & 33 & 33.5 \\
\hline \multicolumn{7}{|c|}{ Heat-related emergency visits } \\
\hline Lag 0 & $1.25^{* * *}(1.23,1.26)$ & $1.27^{* * *}(1.26,1.29)$ & $1.31^{* * *}(1.29,1.34)$ & $1.34^{* * *}(1.31,1.37)$ & $1.38^{* * *}(1.33,1.43)$ & $1.62^{* * *}(1.49,1.76)$ \\
\hline $\operatorname{Lag} 1$ & $1.06^{* * *}(1.04,1.07)$ & $1.07^{* * *}(1.05,1.08)$ & $1.08^{* * *}(1.06,1.10)$ & $1.09^{* * *}(1.07,1.12)$ & $1.11^{* * *}(1.07,1.16)$ & $1.18^{* * *}(1.08,1.30)$ \\
\hline Lag 2 & $0.97^{* * *}(0.97,0.98)$ & $0.97^{* * *}(0.96,0.99)$ & $0.98^{* *}(0.96,0.99)$ & $0.99 \quad(0.97,1.01)$ & $1.05^{*}(1.01,1.09)$ & $1.15^{* *}(1.04,1.26)$ \\
\hline
\end{tabular}

\section{$\underline{\text { Heat-related hospital visits }}$}

\begin{tabular}{|c|c|c|c|c|c|c|}
\hline Lag 0 & $1.10^{* * *}(1.09,1.10)$ & $1.11^{* * *}(1.10,1.11)$ & $1.12^{* * *}(1.11,1.12)$ & $1.13^{* * *}(1.13,1.14)$ & $1.18^{* * *}(1.17,1.18)$ & $1.31^{* * *}(1.28,1.33)$ \\
\hline Lag 1 & $1.03^{* * *}(1.03,1.03)$ & $1.04^{* * *}(1.04,1.04)$ & $1.07^{* * *}(1.06,1.07)$ & $1.09^{* * *}(1.08,1.09)$ & $1.12^{* * *}(1.11,1.13)$ & $1.20^{* * *}(1.17,1.22)$ \\
\hline Lag 2 & $1.04^{* * *}(1.04,1.04)$ & $1.04^{* * *}(1.04,1.05)$ & $1.04^{* * *}(1.04,1.05)$ & $1.05^{* * *}(1.04,1.05)$ & $1.08^{* * *}(1.07,1.08)$ & $1.17^{* * *}(1.15,1.19)$ \\
\hline
\end{tabular}

\section{All-cause mortality}

\begin{tabular}{|c|c|c|c|c|c|c|}
\hline Lag 0 & $1.00^{* * *}(1.00,1.01)$ & $1.00^{* * *}(1.00,1.01)$ & $1.01^{* * *}(1.00,1.01)$ & $1.01^{* * *}(1.01,1.02)$ & $1.02^{* * *}(1.01,1.03)$ & $1.05^{* * *}(1.02,1.08)$ \\
\hline Lag & $1.00 \quad(1.00,1.00)$ & $1.00^{* *}(1.00,1.01)$ & $1.01^{* *}(1.00,1.01)$ & $1.01^{*}(1.00,1.01)$ & $1.01^{*}(1.00,1.02)$ & $1.03^{*}(1.01,1.06)$ \\
\hline Lag 2 & $1.00^{*}(1.00,1.00)$ & $1.00^{*}(1.00,1.01)$ & $1.01^{* *}(1.00,1.01)$ & $1.01^{* * *}(1.01,1.02)$ & $1.02^{* * *}(1.01,1.03)$ & $1.04^{* *}(1.01,1.07)$ \\
\hline
\end{tabular}

\footnotetext{
${ }^{\mathrm{a}}$ : Risk Ratio (RR) and $95 \%$ confidence interval $\left(95 \% \mathrm{CI}\right.$ ) of each outcome with a $0.5^{\circ} \mathrm{C}$ increase above the threshold
}

${ }^{*}: p<0.05,{ }^{* *}: p<0.01,{ }^{* * *}: p<0.001$ 


\section{Figure legend}

Figure 1 Relationship of WBGT with heat-related hospital visits for (a) whole Taiwan and (b) Central Taiwan. The blue bars denote numbers of days in certain WBGT range and the orange line indicates numbers of heat-related hospital visits. Rare events of WBGT above $35^{\circ} \mathrm{C}$ in Central Taiwan may cause fluctuations in counts of heat-related hospital visits.

Figure 2 RaRRs of heat-related emergency visits, heat-related hospital visits and all-cause mortality at different WBGT threshold candidates for whole Taiwan island and different sub-regions (a)(c)(e), different sex and age (b)(d)(f), respectively. $p$-values are those for the corresponding risk ratios at that threshold candidate.

Figure 3 RaRRs of heat-related emergency visits, heat-related hospital visits and all-cause mortality at different temperature threshold candidates for whole Taiwan island and different sub-regions $(a)(c)(e)$, different sex and age (b)(d)(f), respectively. $p$-values are those for the corresponding risk ratios at that threshold candidate

Figure 4 Counts of periods of consecutive days exceeding the specified WBGT thresholds in different regions of Taiwan between 2008 and 2017; (a) same threshold for all regions and (b) regionspecific threshold

Figure 5 Counts of periods of consecutive days exceeding the specified temperature thresholds in different regions of Taiwan between 2008 and 2017; (a) same threshold for all regions and (b) region-specific threshold 
(a)

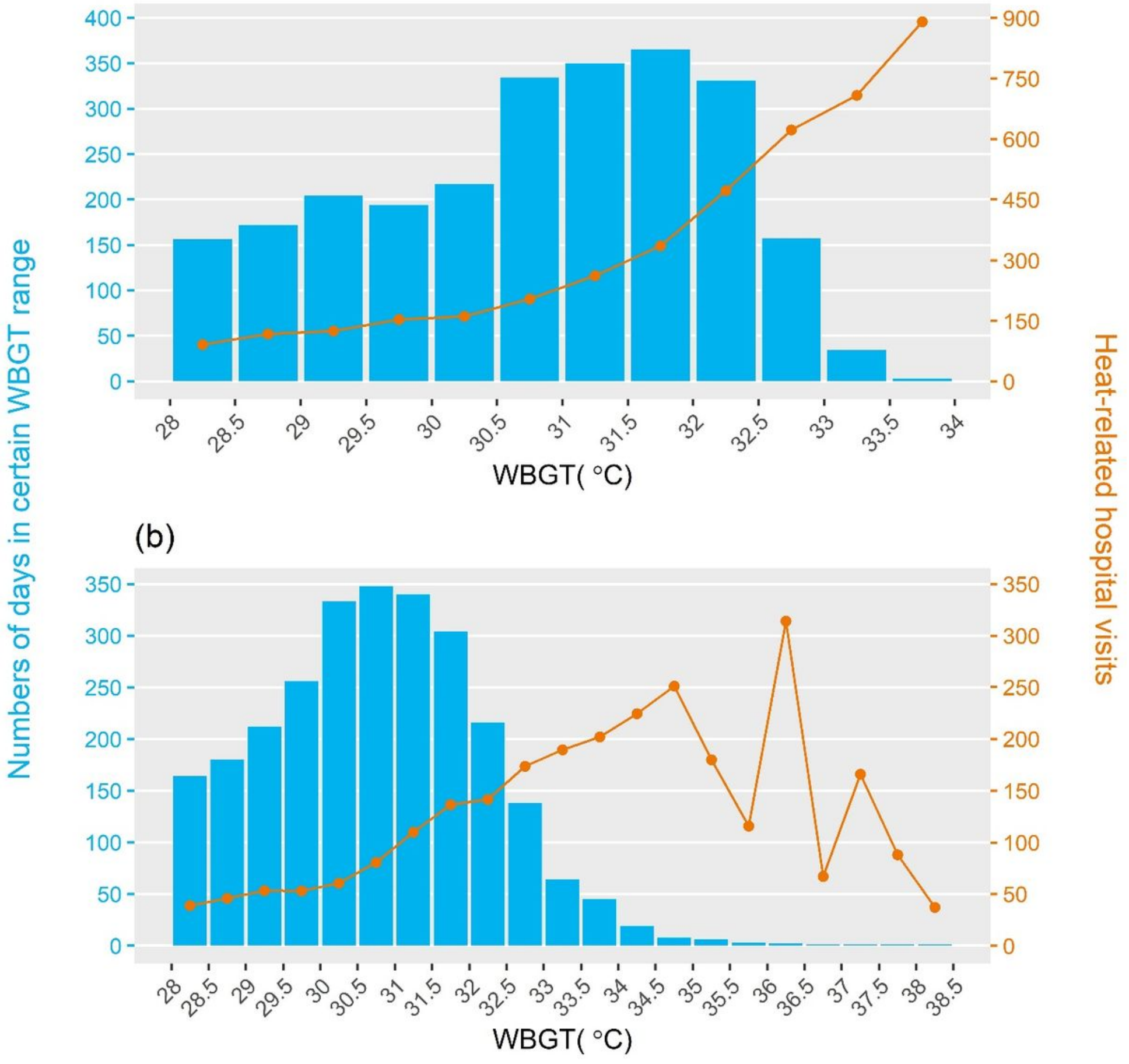

\section{Figure 1}

Relationship of WBGT with heat-related hospital visits for (a) whole Taiwan and (b) Central Taiwan. The blue bars denote numbers of days in certain WBGT range and the orange line indicates numbers of heatrelated hospital visits. Rare events of WBGT above 35पC in Central Taiwan may cause fluctuations in counts of heat-related hospital visits. 

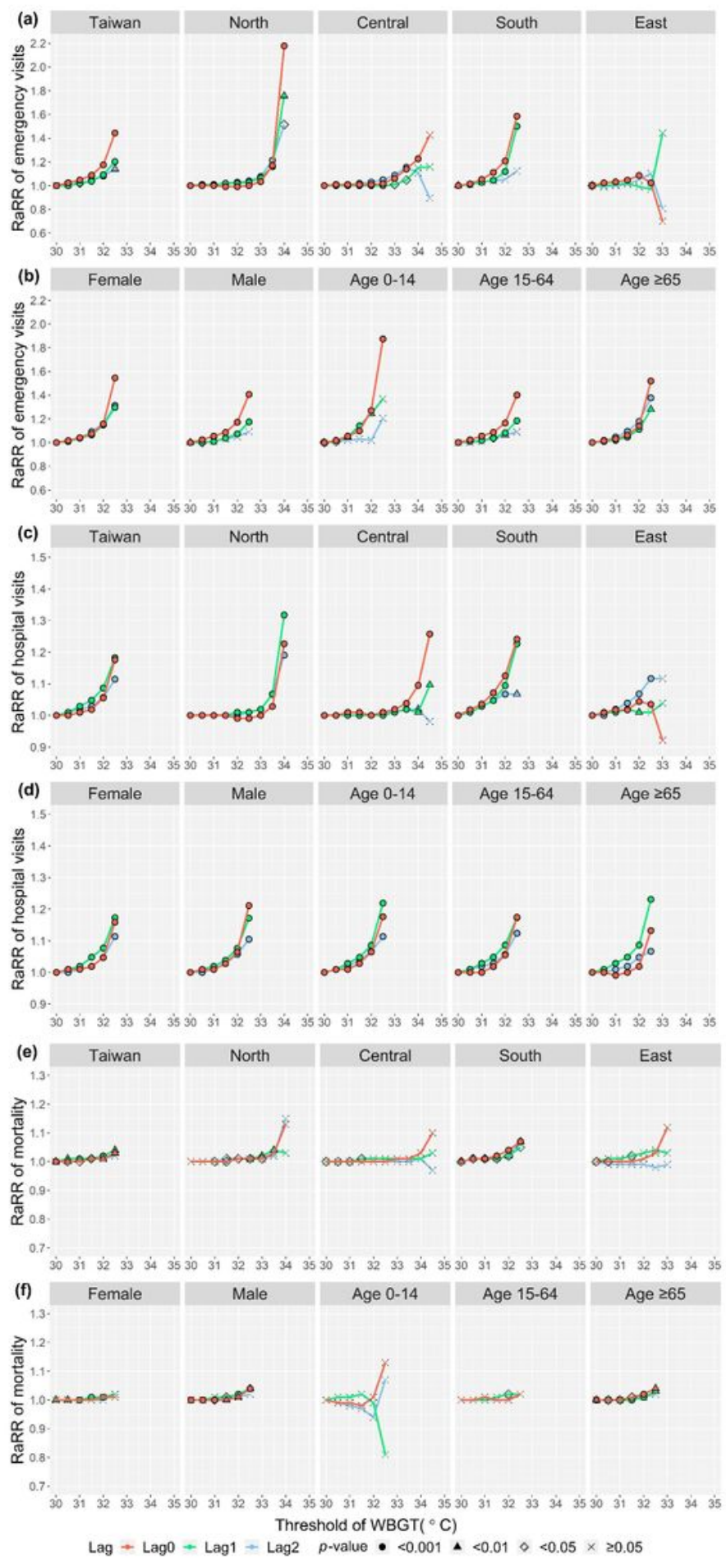

\section{Figure 2}

RaRRs of heat-related emergency visits, heat-related hospital visits and all-cause mortality at different WBGT threshold candidates for whole Taiwan island and different sub-regions (a)(c)(e), different sex and age $(b)(d)(f)$, respectively. $p$-values are those for the corresponding risk ratios at that threshold candidate. 

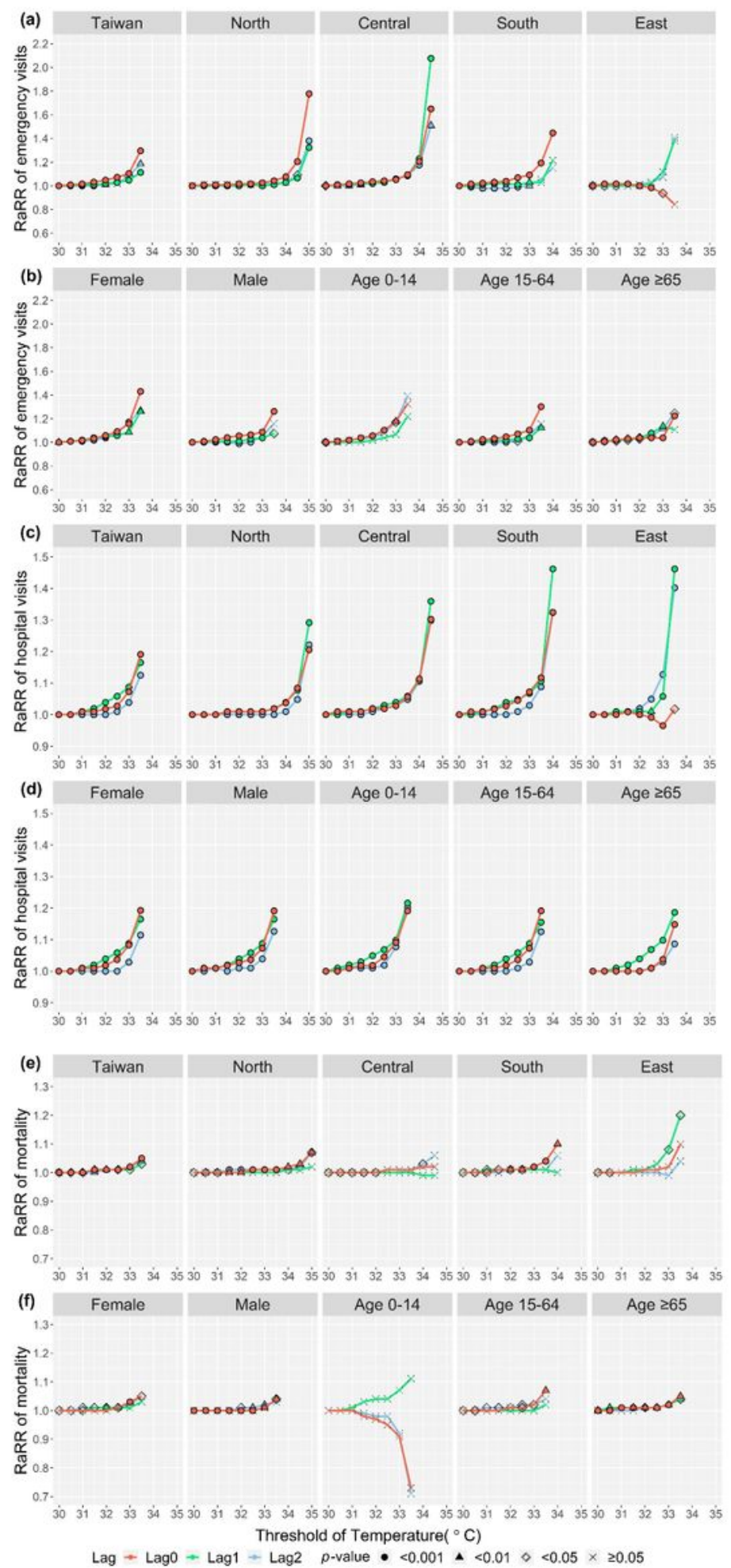

\section{Figure 3}

RaRRs of heat-related emergency visits, heat-related hospital visits and all-cause mortality at different temperature threshold candidates for whole Taiwan island and different sub-regions (a)(c)(e), different sex and age $(b)(d)(f)$, respectively. $p$-values are those for the corresponding risk ratios at that threshold candidate 


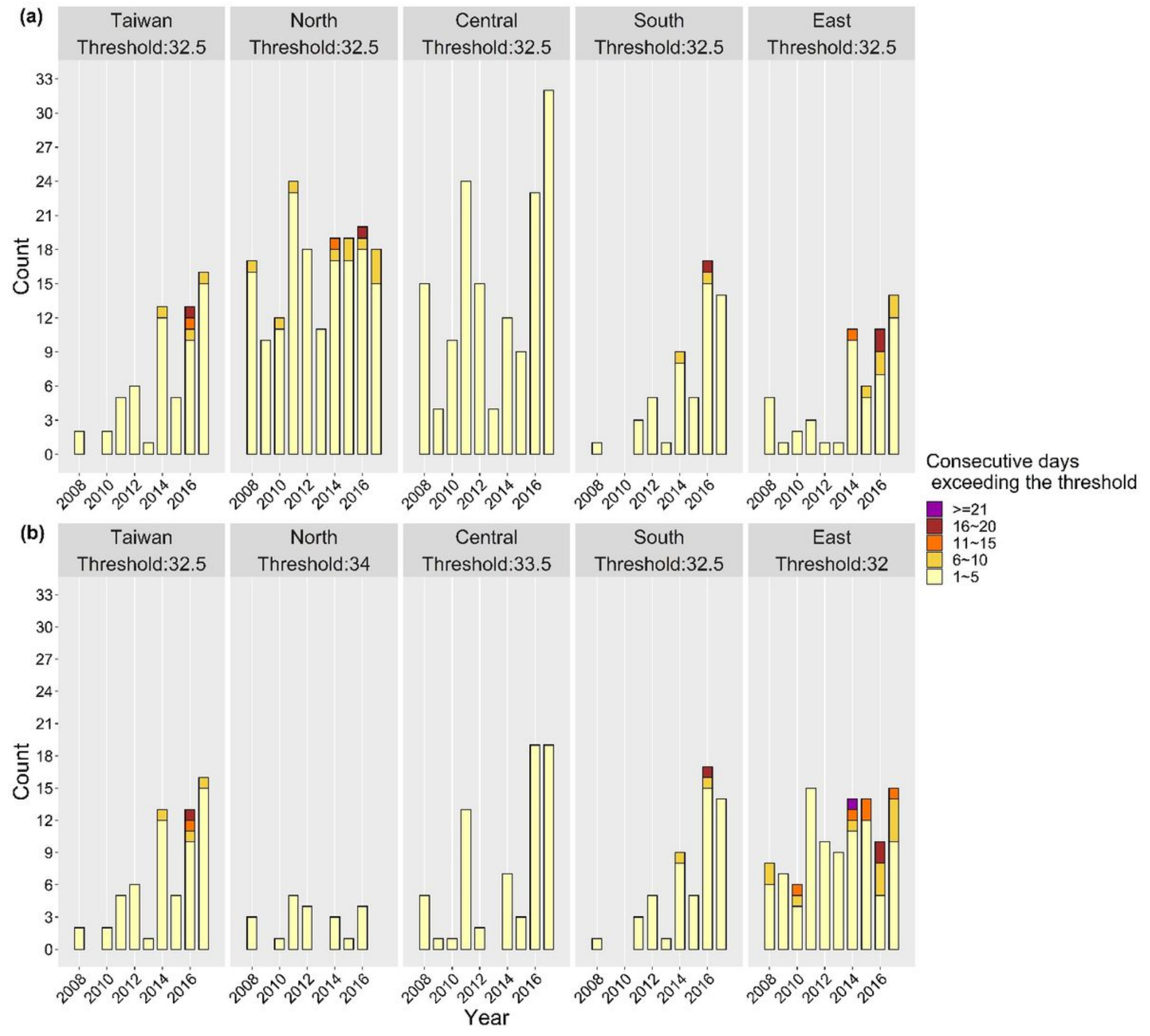

Figure 4

Counts of periods of consecutive days exceeding the specified WBGT thresholds in different regions of Taiwan between 2008 and 2017; (a) same threshold for all regions and (b) region-specific threshold 


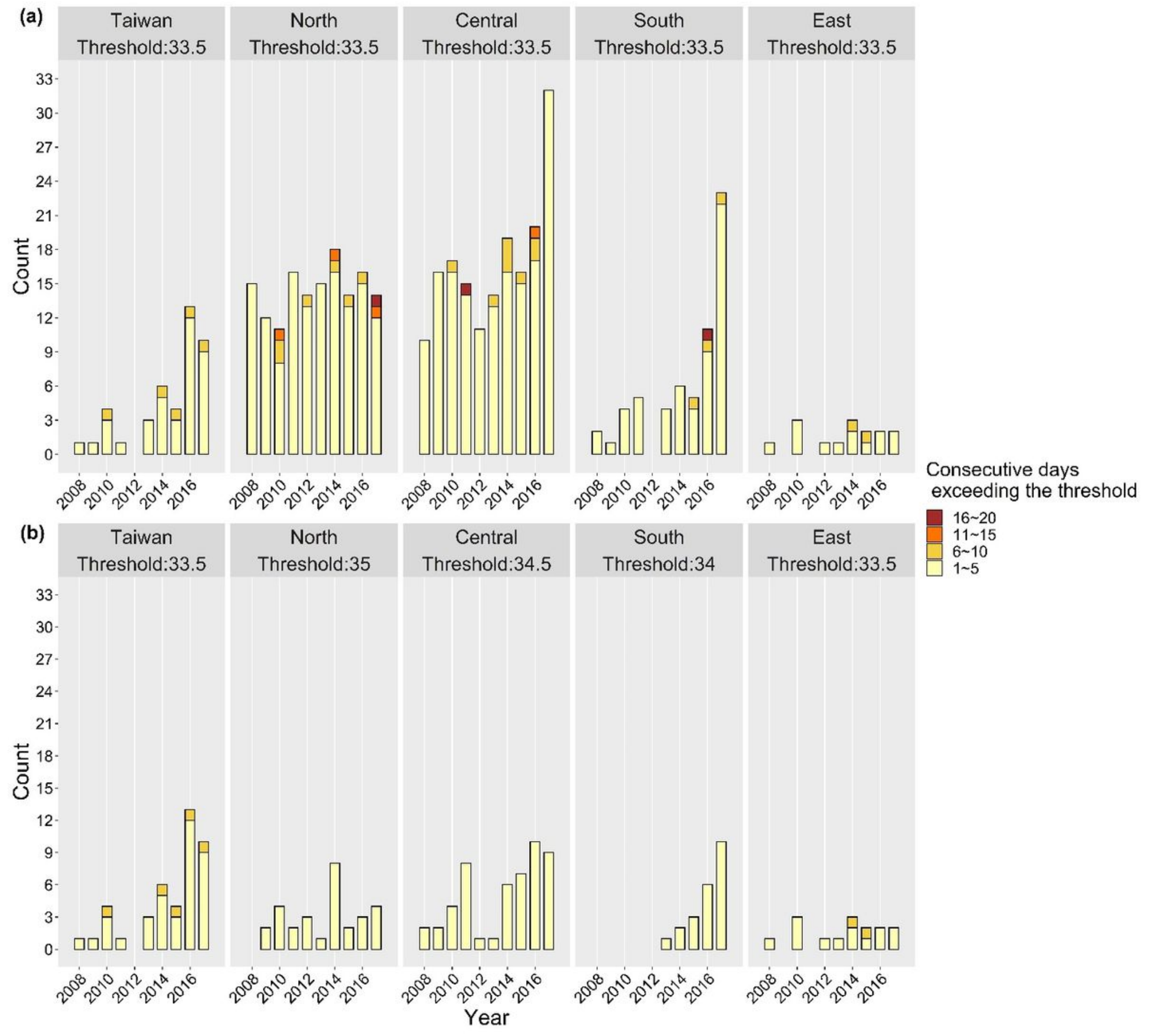

Figure 5

Counts of periods of consecutive days exceeding the specified temperature thresholds in different regions of Taiwan between 2008 and 2017; (a) same threshold for all regions and (b) region-specific threshold

\section{Supplementary Files}

This is a list of supplementary files associated with this preprint. Click to download.

- Supplementalmaterials0401.docx 